\title{
Surface erosion effect on tailings
}

M. Mussé Environment and Infrastructure, AMEC International Ingeniería y Construcción Ltda., Chile

J. Lupo Newmont Mining Company, USA

\section{Abstract}

Due to the high water consumption in process plants, the shortage of water, and its increasing cost in many regions in the world, maximum water recovery from tailings prior to transportation and placement in the tailings storage facility is a necessary outcome for many existing and proposed mines. There are also many other advantages to considering dewatered (thickened, paste, or filtered) tailings as a tailings management option, including improved geotechnical performance, reduced closure/reclamation costs, and even enhanced permitting expediency.

Some properties of dewatered tailings are well understood and proven in an operating environment, whereas others can be defined by standard test procedures, for example, dry density, slump, rheology, and permeability (amongst others). However, some critical parameters, especially performance data, cannot be defined by standard tests and the database on operating dewatered tailings facilities is limited. These parameters include the definition of deposition slopes, erosion effect (hydraulic and wind), post-depositional re-saturation behaviour, and liquefaction susceptibility. The inability of some designers to appropriately identify these critical parameters has led to poor performance with some dewatered tailings facilities.

Even though some of the largest mines and tailings deposits are located in dry areas, they are exposed to extremely large hydrology events (such as the 'Invierno Altiplánico' in the desert in northern Chile). These events may produce significant damage and excessive erosion on the tailings surface.

The objective of this paper is to show the importance of the hydraulic erosion effects and how they could impede or even reverse reclamation work.

\section{Introduction}

Due to the high water consumption in process plants, the shortage of water, and its increasing costs in many regions in the world, maximum water recovery from tailings prior to transportation and placement in the tailings storage facility (TSF) is a necessary outcome for many existing and proposed mines.

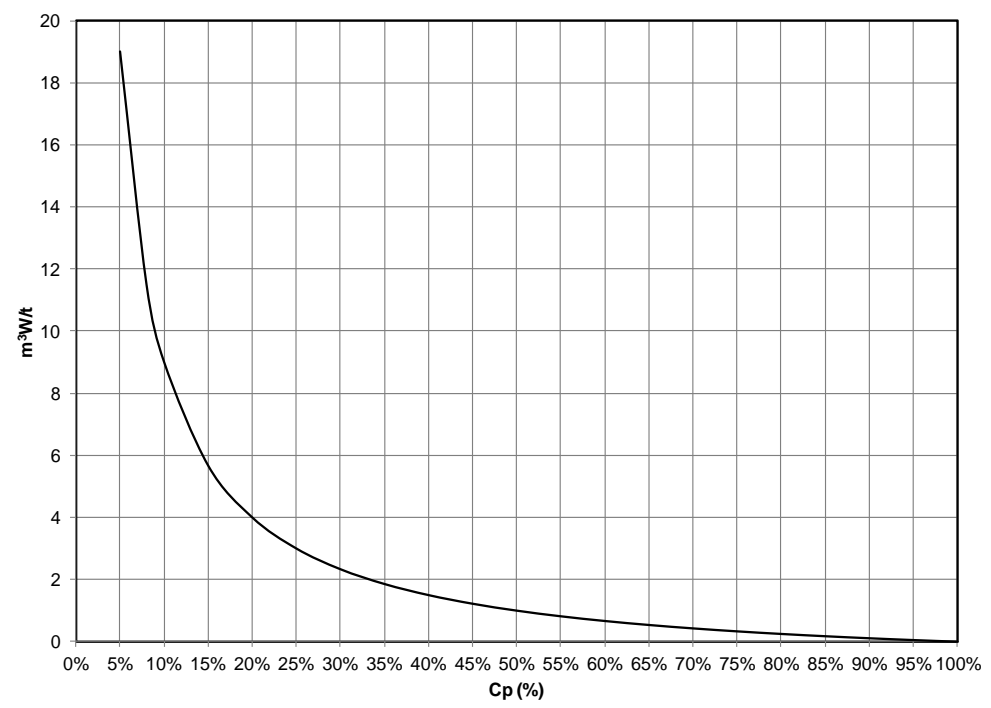

Figure 1 Tailings solids concentration (by weight) versus tailings water content 
As shown in Figure 1, the tailings water content for different tailings solids concentrations (by weight) increases significantly with minor changes in the solids concentration. This simple graph illustrates the high water consumption at a low percentage of solids. It also demonstrates the advantage of increasing the tailings solids concentration (e.g. thickened, paste, and filter tailings) to reduce water consumption.

\section{$2 \quad$ Main advantages}

There are also many other advantages to considering dewatered (thickened, paste, or filtered) tailings as a tailings management option, including improved geotechnical performance, reduced closure/reclamation costs, and even enhanced permitting expediency. Some key issues have been assessed (Fourie, 2012), leading to a conclusion of perceived and realised benefits of the dewatering tailings technology.

Some properties of dewatered tailings are well understood and proven in an operating environment, whereas others can be defined by standard test procedures, for example, dry density, slump, rheology, and permeability (amongst others).

Dewatering costs may increase significantly when the solids concentration is increased, but the costs of water savings are dramatically reduced. Figure 2 shows the tailings continuum with the effects of the dewatering process (Davies et al., 2010).

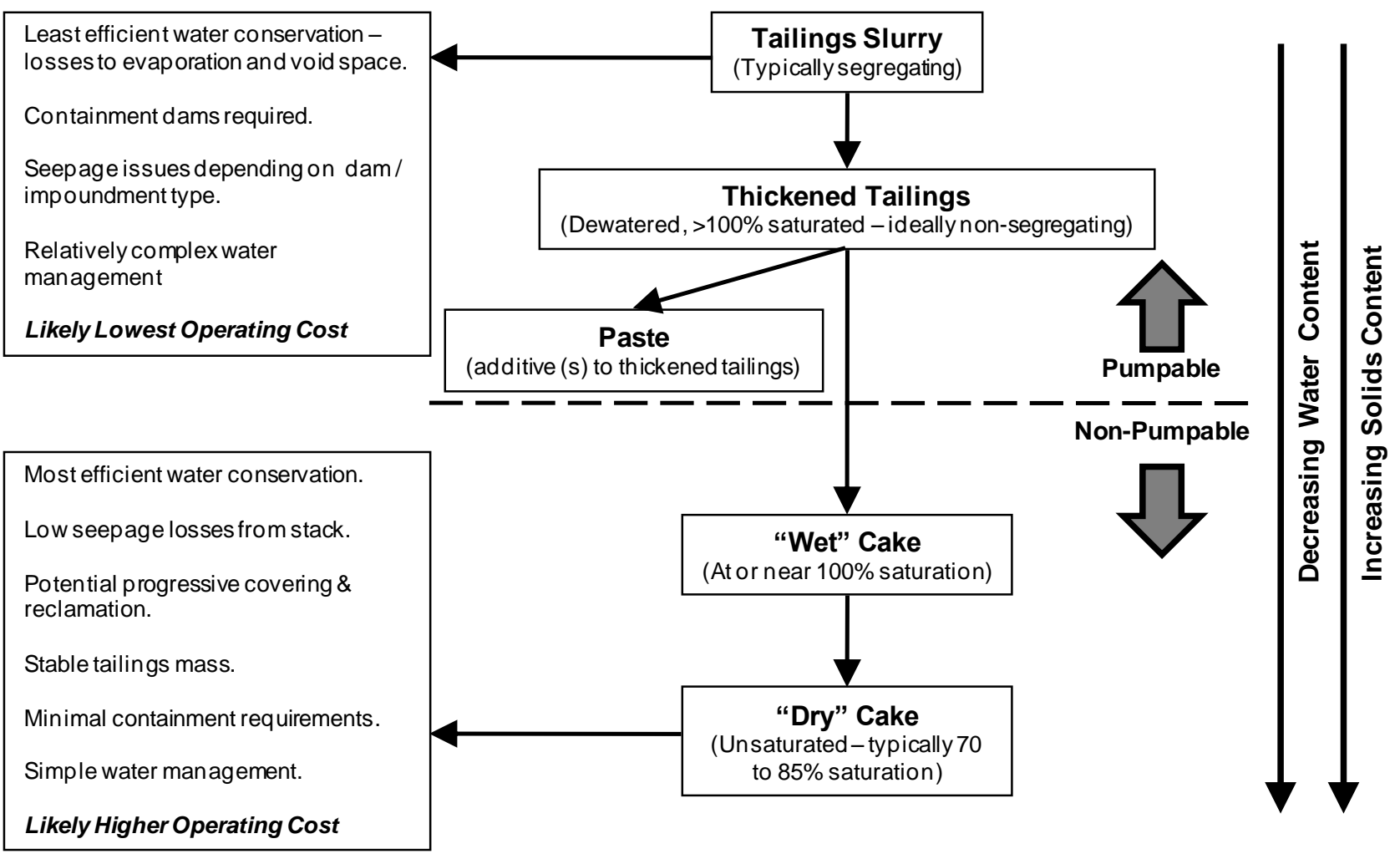

\section{Figure 2 Tailings continuum}

Dewatering tailings also allows the material to be deposited or placed at steeper slopes than that achieved with slurry deposition. While this benefits the operation (through lower water consumption, smaller TSF footprint, etc.), it changes the approach that can be used for closure and reclamation. For example, on one end of the tailings continuum are 'dry' cake or filtered tailings. Filtered tailings have a consistency of moist soil and can be placed and compacted in-place, as with construction materials. Because of their material characteristics, filtered tailings can be stacked at steep slopes (e.g. $3 \mathrm{H}$ to $2.5 \mathrm{H}$ : $1 \mathrm{~V}$ or $33 \%$ to $40 \%$ ) and concurrently reclaimed. However, because these materials can be stacked at steep slopes, the erosion potential will be higher due to the steeper flow gradient and energy. To counter this erosion potential, filtered tailings often have cover systems with a large rock fraction (discussed in Section 4.2.2.). 
Paste tailings, toward the wetter end of the tailings continuum, may be deposited at slopes ranging from 4 to 10 per cent (locally may be steeper), but cannot be reclaimed concurrently. As a result, the paste tailings slope will be exposed for longer periods of time, increasing its potential for erosion, albeit at shallower slopes than with filtered tailings. Since the paste tailings mass will be exposed to erosion for a longer period of time, contingencies need to be made in the TSF design to allow collection of eroded materials and possibly containment of surface water.

So, selection of the tailings type (slurry, thickened, paste, or filtered) not only impacts operational considerations; it also influences closure and reclamation designs.

\section{Critical parameters}

For the most part, tailings characterization work is focused on operational concerns (e.g. water consumption, TSF footprint, pumping, etc.), but very little work has been focused on erosivity of the tailings and its relationship to the following parameters:

- Deposition slopes.

- Particle size distribution (which is influenced by tailings continuum).

- Mineralogy.

- Process additives.

- Post-deposition re-saturation behaviour.

- Post deposition liquefaction susceptibility.

It is the inability of some designers to appropriately identify these critical parameters that has led to some poor performance with TSF and TSF cover systems. Once a tailings type is selected, the designer must consider how the tailings are to be managed and deposited and then decide what design parameters may be important. The design parameters for a TSF change as you move along the tailings continuum (for both operational and closure considerations).

\section{$4 \quad$ Hydraulic erosion effect}

\subsection{General}

In the case of hydraulic erosion, the effect can become critical if it is not taken into account when designing the TSF (operation and closure). Even though some of the largest mines and tailings deposits are located in dry areas, they are exposed to extremely large hydrology events (such the 'Invierno Altiplánico' in the desert in northern Chile). 


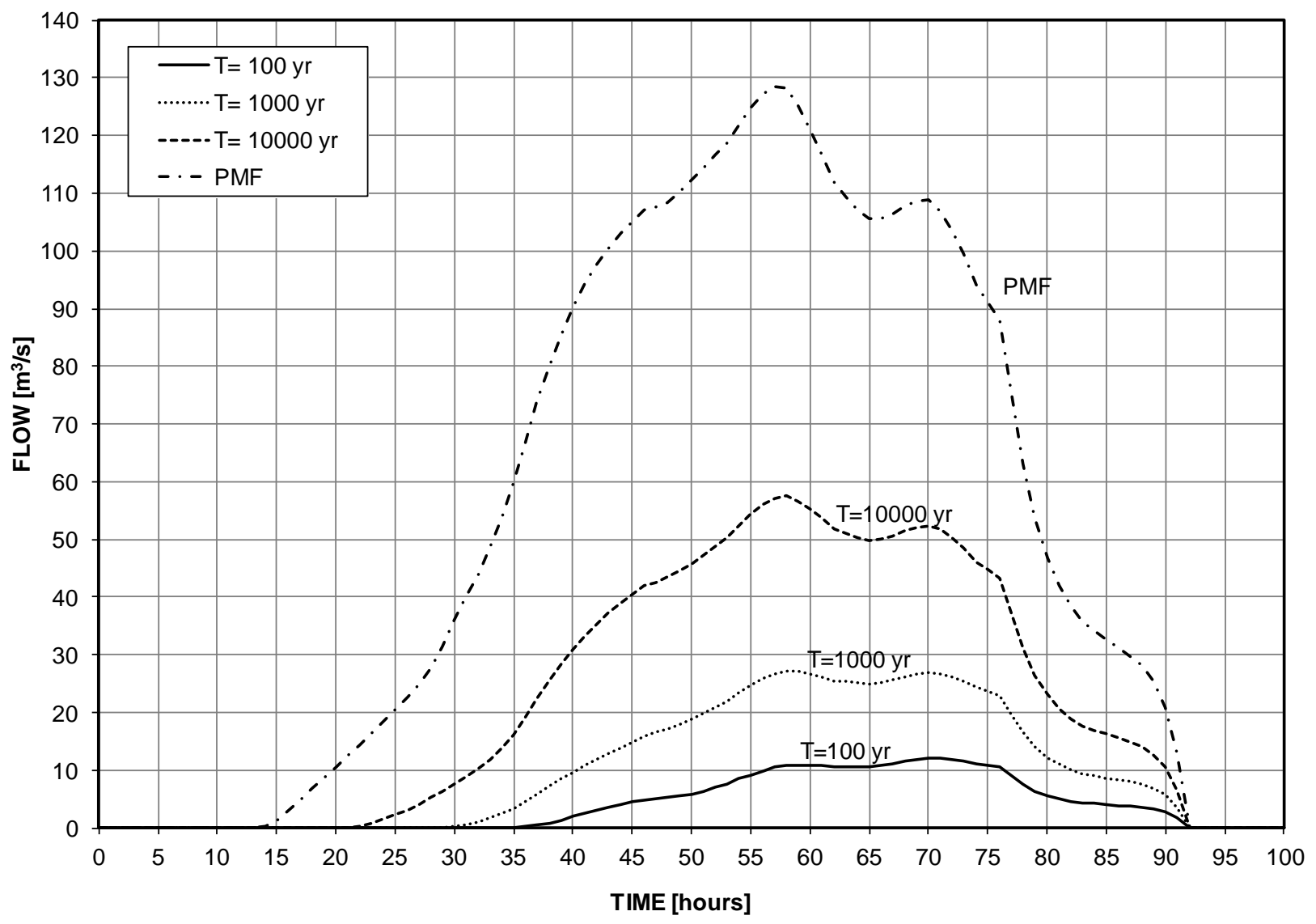

\section{Figure 3 Rainfall hydrographs}

Figure 3 shows hydrographs (72-hour rainfall) corresponding to the 'Invierno Altiplánico' storm events in the desert Copiapó area in northern Chile. A 2 year event (not shown in the figure) may generate a $1.2 \mathrm{~m}^{3} / \mathrm{s}$ peak flow. A 20 year event may generate $4.9 \mathrm{~m}^{3} / \mathrm{s}$. In general, when considering a 'daily basis' (normal conditions), a 20 year event can be considered as 'extreme', mainly because of the effects. Some infrastructure facilities are damaged by these types of events. In this particular case (in the Copiapó area, where the hydrograph shown in Figure 3 was determined), the PMF peak flow can be 26 times larger than the 1,000 year event and the effects can be larger in a similar proportion. In some cases, the difference between the PMF and other extreme events (like the 200 year event, for example) can be about 60 times or even more.

As illustrated in Figure 3, even in very arid regions of the world, the range of precipitation can be quite large, which will impact the design of the TSF as well as the surface water diversion works (i.e. channels) that collect and route non-contact water away from the TSF basin. Often these channels are designed using a low return period storm event, but are easily overtopped when a higher return period event occurs. In some cases, TSFs do not have these types of facilities at all, resulting in significant discharge into the TSF basin. In any case, these diversion works generally are not operative during closure, so large amounts of water are expected to get into the basin (runoff), carrying sediments from the upper catchment areas, and potentially producing significant erosion on the tailings surface.

Regulations typically require the use of the probable maximum flood (PMF) to design the hydraulic works for closure. In the above mentioned areas, the PMF may largely exceed any expectable extreme value.

Normal hydrologic events (not even close to the PMF) may produce significant damage in a variety of structures (naturally consolidated soils, some engineered designed and constructed roads and infrastructure facilities) when water flows from large upstream catchment areas. Thus, potentially significant damage may be expected when a PMF event occurs. 
Figure 4 shows a much more extreme runoff effect when the probable maximum precipitation (PMP) occurs at a site located in the central-north area of Chile. For this site, the PMP would have resulted in a discharge into the TSF basin exceeding 70 million cubic metres, a significant volume to store.

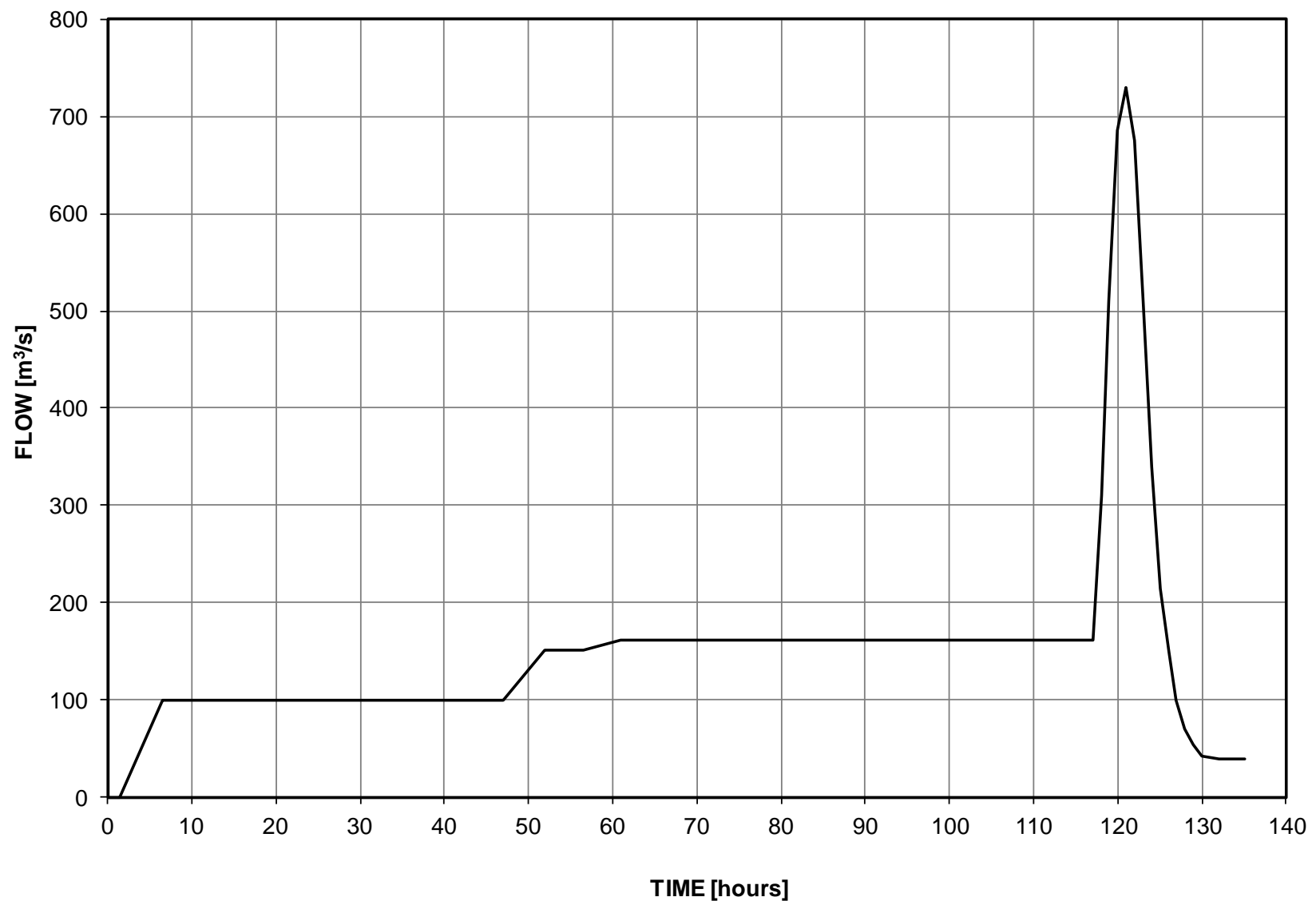

Figure 4 PMF hydrographs

In some cases, due to regulations or corporate and environmental restrictions, facilities have to handle the PMF not only at closure and post-closure but also during operations. Thus, surface tailings configuration and the elevation of the containment embankments must be designed for that condition.

\subsection{Impact on closure}

As stated, large precipitation events may produce significant damage and erosion on the tailings surface and could impede or even reverse reclamation work.

For that reason, it is important for the design to consider the potential effects of the erosion on the tailings surface and to incorporate the corresponding mitigation solutions. Design process must begin with closure, looking towards a long-term physical and geochemical stability. In addition, some countries have new regulations, such as Chile's Law \# 20551, that require financial warranties and bonds to ensure the safe closure (physical and chemical) of the mining facilities.

To assess the impact of precipitation on TSF closure, it is necessary to use a number of tools to predict and quantify the impact so that suitable mitigation measures and designs can be developed.

\subsubsection{Landform evolution models}

Landform obviously plays an important role in the closure aspect for TSFs. There are several available landform evolution models (LEMs) to estimate the erosion effect on the tailings. Some of them simulate the effect of a long-term average precipitation event. SIBERIA (developed by Professor Garry Willgoose at MIT, Boston, in 1989), for example, uses an average area-discharge relationship to determine average sediment 
loss per year and does not use the time series hydrology of a single rainfall event or series of events (Australian Government, 2011). Thus, the impact of an extreme rainfall event (or a series of events comprising an extreme wet season) may not be adequately addressed.

The Cellular Automaton Evolutionary Slope and River (CAESAR), developed by Professor Tom Coulthard, Geography Department, University of Hull, U.K., can use input data from discrete rainfall and runoff events, enabling the effect of extreme rainfall events on landform stability to be simulated (Australian Government, 2011).

Other models evaluate the effect of a single extreme event. For example, Revised Universal Soil Loss Equation (RUSLE) - developed and maintained by the USDA Agricultural Research Service (ARS) in cooperation with the USDA Natural Resources Conservation Service (NRCS), USDI Office of Surface Mining, Reclamation, and Regulation, USDI Bureau of Land Management, Soil and Water Conservation Society, University of Tennessee, Purdue University, and University of Minnesota - evaluates the effect of direct rainfall on the surface (tailings, in this case). The Sediment, Erosion, Discharge by Computer Aided Design (SEDCAD) model (developed by the Civil Software Design, LLC) uses discrete precipitation events to predict the volume of soil lost to erosion through the formation of gullies.

When working with LEMs, the designer needs to make a judgement on the evolution and shape of the tailings surface, which will be a function of the type of tailings to be deposited (see tailings continuum). Given the relatively flat slopes and beaches formed by slurry tailings, this process can be somewhat straightforward. However, predicting the evolution and morphology of thickened and paste tailings over a large area can be challenging, as there are a number of factors influencing the tailings surface shape and slope (e.g. moisture content, deposition rate, particle distribution, mineralogy, etc.), as well as postdeposition changes that may occur. Care must be taken to assess the type of tailings to be deposited and its flow characteristics during and post-deposition.

Filtered tailings are easier to design with LEMs, as the material is placed in a similar fashion as a construction material, so the landform being developed can be predictable and planned as in an earthworks project.

Regardless of the type of tailings being deposited, surface erosion potential must be considered in the TSF design. When beach slopes (typical conventional tailings slurry) are flat (on the order of 1 per cent) erosion tends to be very low, but for steeper beach slopes (generally dewatered tailings), the effect needs to be assessed. Damaging gully erosion associated with water flowing down slopes may become critical.

\subsubsection{Mitigation measurements}

The most common approach to TSF closure design is to focus on cover system designs to mitigate erosion. While cover systems are an important component to closure, it is often difficult to design a simple cover to withstand the potentially highly erosive conditions that may develop with very large precipitation events. It has to be noted that erosion modelling is a relatively immature science that attempts to model the integrated processes and influences of rainfall, runoff, landform geometry and materials, cover protection, and sediment transport to estimate the long-term evolution of landforms due to erosion.

Extensive data collection on erosion, hydrology, and sediment transport is required to ensure adequate model calibration and accuracy in the long-term predictions, which are not always available.

Thus, mitigation measurements should be put in place when designing the TSF. First of all, the tailings beach slope does not necessarily need to be steeper, but rather the most convenient for adequate operation and compatibility with closure.

A proper range of beach slopes should be assessed, varying from the steepest (compatible with operational issues) to the shallowest (compatible with long-term stability). A variety of numerical tools can be used to simulate a wide range of tailings beach slopes when developing a tailings management plan, such as GoldTail, TMS, and SURPAC (Mussé et al., 2007). 
For this reason, the design of key facilities should take into account this range of beach slopes. Plans for containment embankments should consider the required materials for the most conservative case, as well as the constructability, adjusting to the mine schedule.

The configuration of the tailings surface, the lowest point of the tailings surface (where the supernatant pond will be located), and the water recovery system should also take into account the potential variations on the beach slopes when subject to erosion effects.
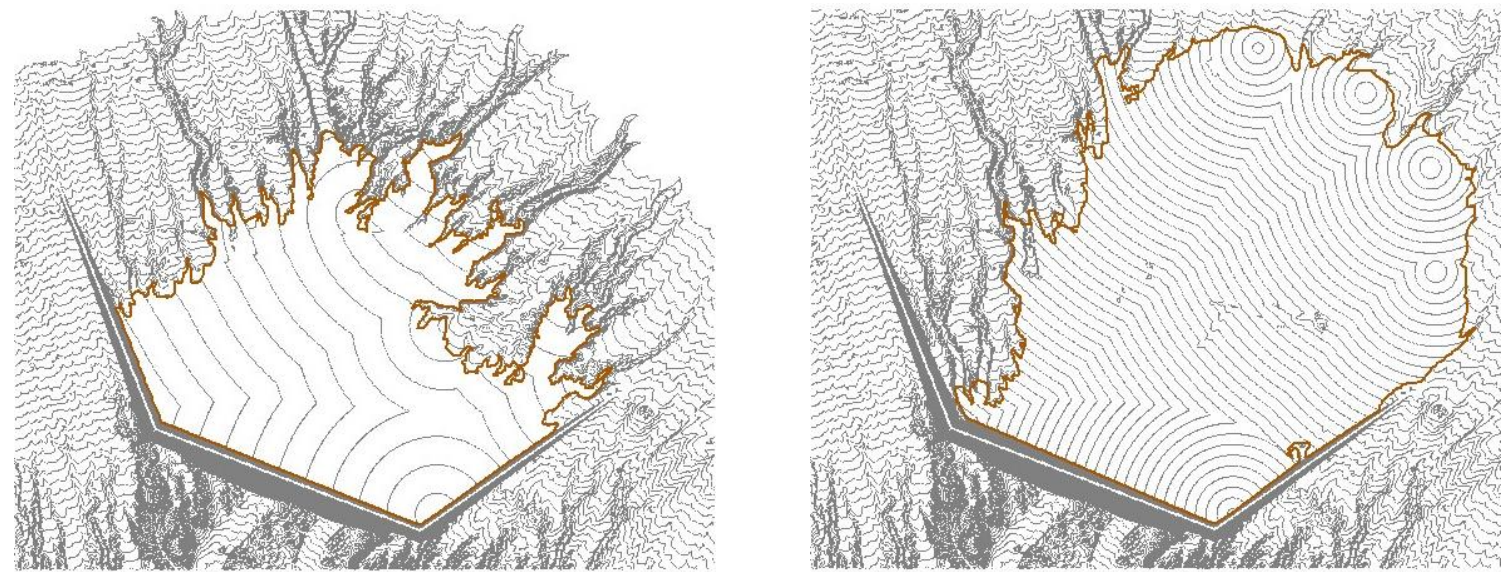

Figure 5 Impact of beach slopes on the tailings configuration and embankments

Figure 5 shows different configurations of the TSF when the tailings beach changes. It can be noted that an embankment's elevation may be significantly higher for flatter angles.

Cover systems may also be part of the long-term stability measurements, but sometimes they can only be in place after operations are complete. Some surface configurations avoid the placement of cover materials in advance, typically when TSFs are located in valleys and tailings discharge has to be implemented around the surface through multiple spigots.

When considering a cover system, it is important to understand that the objectives of a cover system may vary from site to site but generally include the following:

- Dust and erosion control.

- Chemical stabilisation of potentially acid generating tailings (through control of oxygen ingress and/or water infiltration).

- Control of contaminants release (through control of infiltration).

- Provision of a growth medium for establishment of vegetation.

On the basis of their design objectives, the various types of tailings covers can be classified into three categories, (Elander et al., 1998; Ritchie, 1999; DeVos et al., 1999):

- Oxygen barrier covers: These limit the transport of oxygen into the tailings, either by acting as barriers against oxygen diffusion (water cover) or by consuming oxygen.

- Low water flux covers: These aim to inhibit infiltration into tailings. Covers of this type include the low permeability cover (water-shedding cover), the capillary barrier, and the evapotranspiration cover.

- After-use cover: This aims to improve the appearance of the tailings surface, to prevent surface erosion, to limit contact between the tailings and the surface runoff and, if feasible, provides a growth medium for vegetation.

Cover design is site specific depending on the tailings characteristics, climatic conditions, material availability, and the sensitivity of the receiving environment. 
It has to be understood that a TSF is a '1:1 scale model'. Thus, operation monitoring may provide information to update - if needed - some design parameters.

Modelling results have demonstrated that tailings surfaces are likely to result in landscape instability over decadal to centennial time scales (Hancock and Willgoose, 2011), but these timeframes are often not considered in the TSF design. Experience has also shown that erosion losses can be considerable on TSFs, depending on the site conditions and tailings properties. For example, Blight (1989) discusses erosion on large gold tailings facilities in South Africa that do not have significant erosion rates, but the slopes may erode hundreds of tons per year. Annual erosion from agriculture fields rarely exceed 10 to $15 \mathrm{t} /$ ha (Blight, 1989). During extreme events, results may be largely negative.

Experience from the author has shown that erosion rates at some sites in South America could exceed $2,000 \mathrm{t} / \mathrm{ha} / \mathrm{yr}$ considering average hydrology conditions. Analyses were not carried out with large events, so significant impacts may be expected under extreme conditions.

\section{$5 \quad$ Conclusions}

Dewatering tailings allows the material to be deposited or placed at steeper slopes than that achieved with slurry deposition. While this benefits the operation (lower water consumption, smaller TSF footprint, etc.), it changes the approach that can be used for closure and reclamation.

Some critical parameters, especially performance data, cannot be defined by standard tests, and the database on operating dewatered tailings facilities is limited (i.e. the definition of deposition slopes, erosion effect, and post-depositional re-saturation behaviour). It is the inability of some designers to appropriately identify these critical parameters that has led to some poor performance with some dewatered tailings facilities.

On one end of the tailings continuum, filtered tailings have a consistency of moist soil and can be placed and compacted in-place as with construction materials, stacked at steep slopes (e.g. $3 \mathrm{H}$ to $2.5 \mathrm{H}: 1 \mathrm{~V}$ ), and concurrently reclaimed. However, because these materials can be stacked at steep slopes, the erosion potential will be higher due to the steeper flow gradient and energy. To counter this erosion potential, filtered tailing often have cover systems with a large rock fraction.

Paste tailings may be deposited at slopes ranging from 4 to 10 per cent (locally may be steeper), but cannot be reclaimed concurrently. As a result, the paste tailings slope will be exposed for longer periods of time, increasing its potential for erosion, albeit at shallower slopes than with filtered tailings. Since the paste tailings mass will be exposed to erosion for a longer period of time, contingencies need to be made in the TSF design to allow collection of eroded materials and possibly containment of surface water.

So, selection of the tailings type (slurry, thickened, paste, or filtered) not only impacts operational considerations; it also influences closure and reclamation designs.

Some large mines located in dry areas are exposed to extremely large hydrology events that may produce significant damage and erosion on the tailings surface and could impede or even reverse reclamation work.

There are several available landform evolution models (LEMs) to estimate the erosion effect on the tailings (whether long-term average events or the effect of a single extreme event). This is a relatively immature science that attempts to model the integrated processes and influences of rainfall, runoff, landform geometry and materials, cover protection, and sediment transport to estimate the long-term evolution of landforms due to erosion. It requires extensive data collection on erosion, hydrology, and sediment transport to ensure adequate model calibration and accuracy in the long-term predictions, which are not always available.

For that reason, mitigation measurements are necessary when designing the TSF, considering that the tailings beach slope does not have to be the steepest, but rather the one most compatible with the operation management and the closure design. 
A proper range of beach slopes should be assessed, varying from the steepest (compatible with operational issues) to the shallowest (compatible with long-term stability). A variety of numerical tools can be used to simulate a wide range of tailings beach slopes when developing a tailings management plan.

For this reason, the design of main facilities should take into account this range of beach slopes. Plans for containment embankments should consider the required materials for the most conservative case, as well as the constructability, adjusting to the mine schedule.

\section{References}

Australian Government (2011) Department of Sustainability, Environment, Water, Population and Communities, Post-mining landform stability, viewed 12 January 2011, www.environment.gov.au/ssd/research/hgp/landform-stability.html, last updated 26 March 2011.

Blight, G.E. (1989) Erosion losses from the surfaces of gold-tailings dams, Journal of the South African Institute of Mining and Metallurgy, Vol. 89(1), pp. 23-29.

Davies, M., Lupo, J., Martin, T., McRoberts, E., Mussé, M. and Ritchie, D. (2010) Dewatered tailings practice: Trends and observations, tailings and mine waste, 2010, The Organizing Committee of the 14th International Conference on Tailings and Mine Waste (eds), CRC Press, Portland, Oregon, USA, pp. 132-142.

DeVos, K.J., Ritchie, D.G. and Bocking, K.A. (1999) Practical considerations for covering sulphidic tailings deposits situated above the groundwater table, in Proceedings Sudbury 99, Mining and Environment II, Ontario, Canada, 13-17 September 1999, pp. 291-300.

Elander, P., Lindvall, M. and Hakansson, K. (1998) Prevention and control of pollution from mining waste products, state-of-the-art report, Mitigation of the Environmental Impact from Mining Waste (MiMi), MiMi Print, Sweden, Linköping, pp. 2-29.

Fourie, A. (2012) Perceived and realised benefits of paste and thickened tailings for surface deposition, in Proceedings 15th International Seminar on Paste and Thickened Tailings (Paste 2012), R.J. Jewell, A.B. Fourie and A. Paterson (eds), 16-19 April 2012, Sun City, South Africa, Australian Centre for Geomechanics, Perth, Australia, pp. 53-64.

Hancock, G.R. and Willgoose, G.R. (2011) Gully development, evolution and erosion using a landscape evolution model, in Proceedings 19th International Congress on Modelling and Simulation, 12-16 December 2011, Perth, Australia.

Mussé, M., Eldridge, T., Barrientos, M. and Silva, M. (2007) Modeling tools for development of tailings management plans, in Proceedings 10th International Symposium Environmental Issues and Waste Management in Energy and Mineral Production - SWEMP, 11-13 December 2007, Bangkok, Thailand, Curran Associates, Inc., New York, pp. 227-34.

Ritchie, D.G. (1999) A discussion of seismic design considerations for soil covers on tailings, in Proceedings Sudbury 99, Mining and Environment II, Ontario, Canada, 13-17 September, D. Goldsack, N. Belzile, P. Yearwood and G. Hall (eds), Mineral Exploration Research Centre, Laurentian University, Sudbury, Ontario, pp. 49-58. 
